\title{
PESQUISA DESCRITIVA-ANALÍTICA COM JOGOS: Funções Interativas De Jogos Do Gênero Drama Interativo.
}

\section{ANALYTICAL-DESCRIPTIVE RESEARCH WITH GAMES: Interactive Functions of Games from the Interactive Drama Genre.}

\author{
Ana Carolina Generoso de Aquino ${ }^{1}$, Bela \\ Bruno Serviliano Farias ${ }^{2}$, M.Sc. \\ (1) Universidade Federal do Maranhão \\ e-mail: carol.aquino31@hotmail.com \\ (2) Universidade Federal do Maranhão \\ e-mail: brunoserviliano@gmail.com
}

Análise de Jogos, Design de Interação, Drama Interativo.

Este trabalho tem como objetivo desenvolver uma proposta de análise de jogos digitais do gênero Drama Interativo, com foco nos elementos e funções interativas. Empregando o método descritivo-analítico foi possível constatar como as heurísticas podem instruir o desenvolvimento da arquitetura da informação bem como a apresentação dos elementos interativos.

Game Analysis, Interaction Design, Interactive Drama.

This work aims to develop a proposed analysis for digital games of the genre Interactive Drama, focusing on its elements and interactive functions. Through the descriptive-analytic method, it was possible to verify how heuristics can instruct the development of the information architecture as well as the presentation of the interactive elements.

\section{Introdução}

A importância dos jogos enquanto mídia interativa se faz presente de maneira gradativa. Luz (2009) apresenta um histórico completo dos games, especialmente em sistemas lúdicos digitais, onde é possível observar que desde o início, tais sistemas foram capazes de ter um apelo comercial e emocional principalmente por se tratarem de uma nova maneira de interação lúdica.
Com o passar do tempo, a convergência entre o cinema e seus elementos característicos com interações lúdicas digitais ocorreu de forma natural, através da capacidade dos movimentos de câmeras e maior exploração narrativa em jogos digitais. Esta união resultou em um novo gênero conhecido como Dramas Interativos, advindo dos 


\section{$16^{\circ}$ \\ ERGODESIGN USIHC CINAHPA}

jogos de Aventura e RPG ${ }^{1}$ - Role Playing Game ou Jogo de Representação de Papéis - que teve sua primeira menção por Bates em 1992 como uma nova forma de exploração da inteligência artificial. Tais sistemas são interativos e o usuário se envolve com seus elementos de forma dinâmica e imprevisível ou, pelo menos, não tão linear.

Assim, compreende-se a necessidade de avaliar os componentes desse sistema, homem e computador e suas relações. Tais relações apresentam um novo campo de estudos para a Interação Homem-

Computador por se tratar de uma forma de integrar informação em uma estética cinematográfica com elementos interativos. A presente pesquisa envolve as interfaces, os elementos gráficos e o ambiente imersivo, buscando descrever e analisar os jogos de Drama Interativo a fim de investigar seus componentes interativos, sua interface e elementos gráficos. O principal intuito é desenvolver um método de análise desses sistemas interativos.

\section{Jogos Digitais e o Drama Interativo}

Drama Interativo é uma tradução direta da expressão Interactive Drama, que teria como definição um gênero de jogo narrativo no qual o usuário incorpora um ou mais personagens em determinada história. O percurso no ambiente de interação lúdica digital culmina com o encontro com outros personagens autorizados por inteligência artificial. A interação dá-se ao escolher todas as ações da narrativa deste(s) personagem(s) (SZILAS, 2004). Brandão (2012) menciona que as principais convergências entre elementos cinematográficos e games ocorreram a partir da sexta geração de videogames, nas quais houve um destaque para multijogadores, com maior interação da conexão da internet e o nascimento de grandes jogos online.

Essa multidisciplinaridade advinda deste gênero e também de outros, é algo que representa a necessidade humana natural de tentar maximizar

\footnotetext{
${ }^{1}$ Originários a partir da tradição de jogos de papel e lápis iniciada em1970, onde jogadores assumiam papéis de guerreiros, magos, sacerdotes, etc. Explorando um mundo de fantasia e coletavam tesouros e objetivos (NOVAK, 2010).
}

sua imersividade, experiências interativas e expressividade narrativa enquanto jogador.

\section{Interface e Elementos Interativos}

No presente estudo, os elementos visuais serão analisados partindo do esquema de Twyman (1982, apud PETTERSON, 2002) (fig. 1) no qual a

linguagem é o canal de comunicação e divide-se em elementos gráficos e não gráficos. Optou-se em analisar apenas os elementos gráficos que, por sua vez, subdivide-se em: verbal, pictórico e esquemático.

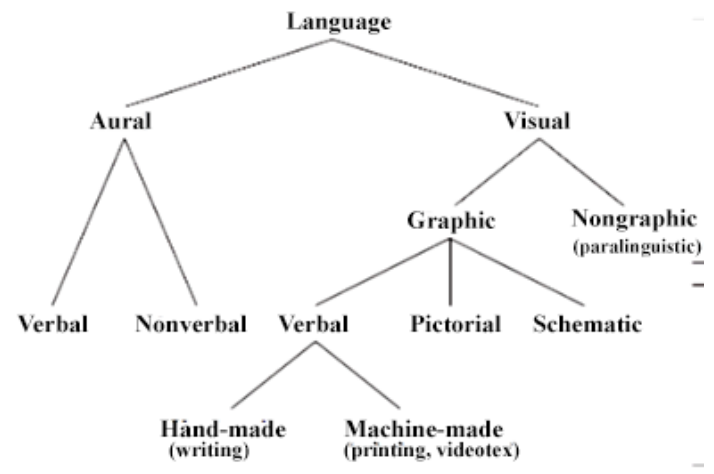

Figura 1 Esquema de Twyman. (Fonte: Petterson, 2002).

A partir dos elementos visuais gráficos se observam os elementos interativos. Salen e Zimmerman (2012) conceituam a interação como uma relação ativa entre duas coisas e referenciam Crawford (1997) que define a interatividade como um processo cíclico, onde há a entrega e o envio de informações. Para que a análise dos jogos se observou a necessidade de utilizar diretrizes. Para isso foram adotadas as divisões de Novak (2010) e Xavier (2010):

- Interface Basilar - se trata de subsistemas visuais funcionais relacionado à virtualidade interativa.

- Interface Simbólica - assume o papel do conteúdo visual disposto durante o processo do jogo. Aplica-se a toda e qualquer representação visual utilizada para dialogar com o jogador. 


\section{$16^{\circ}$ \\ ERGODESIGN USIHC CINAHPA}

Buscou-se a simplificação destas divisões além de priorizar aquelas que seriam relevantes e constantes dentro dos jogos do gênero Drama Interativo. Sendo assim, foram selecionadas as seguintes divisões: Tela de Instrução; Telas de Menu; Telas de Submenu; e Interface Lúdica.

As telas de instrução servem como locais de explanação de possíveis procedimentos necessários e esperados do usuário enquanto jogador atuante. As telas de mеnu apresentam as informações iniciais que devem ser acionadas pelo usuário para adquirir controle do sistema. Os submenus são espaços que apresentam outros elementos de atenção e configuração, correspondendo a um segundo nível hierárquico de informação (XAVIER, 2010). A Interface Lúdica é mais complexa em comparação as outras divisões apresentadas anteriormente devido a quantidade de suas ramificações. Xavier (2010) comenta que a interface lúdica é apresentada pelos elementos visuais encontrados durante a interação lúdica. Por isso envolve os elementos pictóricos, verbais e esquemáticos, o fluxo de informação, a narrativa do jogo, as formas interativas impactando no processo cognitivo.

\section{Impacto Cognitivo}

Os jogos de console vêm exigindo cada vez mais um nível de engajamento e reflexão, para a então alcançar uma resposta que já não o torna totalmente uma cognição experimental. Rogers, Helen e Preece (2013) relacionam os processos cognitivos que podem ser envolvidos em qualquer interação humano-computador. Por esta pesquisa não analisar o usuário diretamente, apenas a interface com a qual ele terá contato, levar-se -á em consideração apenas os processos cognitivos da Multitarefa e Atenção; Memória e Percepção.

Nesse sentido os elementos gráficos desempenham importantes funções no processo cognitivo podendo facilitar a compreensão, chamar a atenção, auxiliar a memorização, etc. Santaella (2005) classifica os elementos visuais em:

- Forma Figurativa - São formas referenciais que apontam para objetos ou situações $16^{\circ}$ Ergodesign - Congresso Internacional de Ergonomia e Usabilidade de Interfaces Humano Tecnológica: Produto, Informações Ambientes Construídos e Transporte

$16^{\circ}$ USIHC - Congresso Internacional de Ergonomia e Usabilidade de Interfaces Humano Computador

CINAHPA | 2017 - Congresso Internacional de Ambientes Hipermídia para Aprendizagem. reconhecíveis para fora da representação. Tem vocação mimética, alinha-se à realidade do usuário e conteúdo naturalizados anteriormente;

- Não-Representativos - Redução da declaração visual de elementos puros como cores, contornos, movimentos, texturas e formas;

- Forma Representativa - Forma visual convencionada, pode compreender qualquer sistema visual codificado como ideogramas, formas de escrita, etc;

\section{Métodos de Análise}

Para este estudo adotou-se metodologia de Inspeção Indireta Sistemática que se baseia no conceito de Gil (2002) e Moraes e Mont'Alvão (2009) no qual, a técnica de observação verifica o sistema analisado de acordo com as variáveis citadas dos elementos visuais e interativos.

A ferramenta de apoio foi formulada em uma estrutura simples, com categorias sucintas, onde a identificação e registro foram analisados quantitativamente de acordo com a seguinte classificação:

1. Tela de Instrução - analisando seus elementos gráficos (pictóricos e verbais) e subdividida em:

- Síncronas, quando a informação é apresentada durante a execução do jogo e;

- Assíncronas, quando a informação é exibida em um momento diferente da execução do jogo.

2. Tela de Menu - analisando seus elementos gráficos (pictóricos e verbais) e sua forma de apresentação, subdividida em:

- Referente, quando dá destaque a atmosfera expressiva do jogo;

- Metafórico, quando utiliza elementos importados do universo visual do jogo para diferenciação e;

- Neutral, quando apresenta telas que não trazem necessariamente consigo a expectativa do jogo, sendo construídas em torno de 


\section{$16^{\circ}$ \\ ERGODESIGN USIHC CINAHPA}

texto e formas geométricas básicas.

3. Tela de Submenu - Possui as mesmas variáveis das telas de Menu, apenas com o acréscimo das variações de seu posicionamento, podendo assumir a forma:

- Desdobrada, quando estas permitem a visualização dos itens anteriores, ou mesmo de outra tela de тепи.

- Segmentada, quando são construídas em páginas que ocupam a tela por completo como páginas consecutivas sob os itens anteriores.

4. Interface Lúdica - Compreende todas as telas em que o jogo é executado, onde se inspecionou os elementos informativos e textuais, cinemáticas (dramáticas ou complementares), a quantidade de personagens jogáveis e o feedback (síncrono ou assíncrono e seus elementos gráficos);

5. Controles - Subdivididos em acionamento tradicional, sensível ao toque ou movimento.

Utilizou-se a plataforma PlayStation 4 para selecionar os jogos por considerar a influência deste dispositivo nas comunidades de games devido ao seu sucesso de vendas.

A seleção dos jogos ocorreu considerando as datas de lançamentos, popularidade e reconhecimento do público, são eles: Until Dawn (Jogo 1); The Wolf Among Us (Jogo 2); Life is Strange (Jogo 3); Game Of Thrones (Jogo 4); Heavy Rain (Jogo 5); The Walking Dead: Game of The Year Ed. (Jogo 6) e Beyond Two Souls (Jogo 7).

O registro visual se fez mediante a captura das telas a partir de cada nova instância e elemento gráfico e interativo observado. Para a tabulação dos dados observados foram utilizados valores numéricos indicando a presença ou ausência de cada elemento avaliado. $16^{\circ}$ Ergodesign - Congresso Internacional de Ergonomia e Usabilidade de Interfaces Humano Tecnológica: Produto, Informações Ambientes Construídos e Transporte

$16^{\circ}$ USIHC - Congresso Internacional de Ergonomia e Usabilidade de Interfaces Humano Computador

CINAHPA | 2017 - Congresso Internacional de Ambientes Hipermídia para Aprendizagem.

\section{Análise dos Resultados}

Foi possível analisar os resultados comparando-os com as heurísticas de Nielsen (apud BARBOSA e SILVA, 2010, p. 316) no qual se trata de um conjunto de requisitos originado a partir da análise de problemas identificados por diversos especialistas em IHC. Os adotados para a análise e observados na pesquisa estão apresentados a seguir.

\subsection{Visibilidade Do Sistema e Feedback}

Para este requisito, têm-se os feedbacks síncronos e assíncronos apresentados pelos jogos analisados, que além de fornecerem uma resposta a ação do usuário durante o percurso do jogo, apresenta uma redundância deste feedback, para que o usuário possa recordar das decisões tomadas, fora do ambiente lúdico. Assim, o feedback se relaciona com a visibilidade do sistema, a partir da redundância de informação em vários momentos interativos. $\mathrm{O}$ feedback nestes jogos se apresenta tanto na forma síncrona quanto assíncrona, ou seja, dentro e fora do ambiente lúdico, durante e depois da interação, utilizando elementos pictóricos e verbais em conjunto ou isoladamente.

Nos menus e submenus há uma sobrecarga de informações tanto de elementos verbais quanto visuais devido ao grande conteúdo disponível no jogo, utilizando constantemente a redundância da informação para auxiliar o jogador em sua navegação por essas telas e também explorá-las em sua totalidade.

\subsection{Correspondência Entre o Sistema e o Mundo Real}

Observados tanto na interface lúdica, que correspondem aos elementos informativos e textuais; quanto nas Telas de Menu e Submenu através dos elementos pictóricos e verbais. Empregam elementos do mundo real em suas estruturas interativas. Observa-se a constante utilização de elementos gráficos pictóricos que remetem ao controle. Utilizando as mesmas representações do controle interativo físico para facilitar a associação e a aprendizagem.

Há diferentes formas de acionamento do controle para interagir com aquela cena, mimetizando os 


\section{$16^{\circ}$ \\ ERGODESIGN USIHC CINAHPA}

$16^{\circ}$ Ergodesign - Congresso Internacional de Ergonomia e Usabilidade de Interfaces Humano Tecnológica: Produto, Informações Ambientes Construídos e Transporte

$16^{\circ}$ USIHC - Congresso Internacional de Ergonomia e Usabilidade de Interfaces Humano Computador

CINAHPA | 2017 - Congresso Internacional de Ambientes Hipermídia para Aprendizagem. gestos do personagem na tela com os gestos que ele executaria no controle.

\subsection{Tomadas de Decisões e Liberdade Lúdica}

Para os jogos analisados, o erro é aceito como forma de aprendizagem e também como uma maneira de progredir no jogo, sendo possível, inclusive, observar momentos em que o próprio sistema induz o usuário ao erro tendo em vista seu progresso com o personagem. Como pode ser observado a partir da coleta de dados do feedback que poderia induzir ou não o usuário ao erro. Não há um percurso "correto" a ser seguido e as escolhas do jogador levarão a diferentes consequências em seu futuro, ainda que $o$ percurso a se seguir seja pré-determinado até certo ponto, os finais diferem a partir das escolhas do usuário enquanto jogador.

\subsection{Projeto Estético e Minimalista}

A interface do jogo durante sua execução, em sua interface lúdica, é extremamente simples, com elementos informativos e textuais presentes apenas mediante necessidade de acionamento, mesmo as identificações de objetos passíveis de interação são identificadas da maneira mais sutil possível, buscando justamente as características de uma cinematografia. Foi possível constatar através da inspeção que para este gênero de jogo busca-se uma interface onde tanto os elementos informativos quanto textuais apareçam de forma sutil, como uma extensão do ambiente em que o jogo se passa, sempre respeitando os ângulos em que a câmera se posiciona. Ou seja, há uma exibição mínima de elementos fixos durante a interface lúdica quando o jogo é executado.

\subsection{Prevenção de Erros}

Em alguns momentos do jogo é possível observar a prevenção de possíveis erros, como o carregamento incorreto de um arquivo de salvamento, ou a saída indesejada do jogo para o menu principal dentro das telas de Menu, Submenu e na própria Interface Lúdica de maneira assíncrona - o que ocasionaria a perda do progresso do jogador. Contudo, na Interface

Lúdica em si, na maioria das ações do usuário para Dramas Interativos em específico, como mencionado anteriormente, não há a escolha incorreta em determinada ocasião ou mesmo caminho incorreto da narrativa a se seguir. Assim, qualquer caminho guiará o jogador a um final, sendo este diferente para cada opção escolhida durante seu percurso do jogo.

\subsection{Processo Cognitivo}

Observou-se que sobre o processo Multitarefa e Atenção os elementos informativos e interativos são destacados a fim de orientar a percepção dos usuários e reduzir a sobrecarga informativa durante a narrativa do jogo em si. Assim, o jogador pode, durante a interação lúdica, realizar multitarefas uma vez que o sistema dosa e destaca a quantidade de informação para deixar os processos cognitivos do jogador livre para o ambiente lúdico em si.

A Percepção engloba as diferentes formas de transmissão da informação e pode ser assimilada por diferentes órgãos sensitivos. É comum no gênero Dramas Interativos estimular tanto visual e sonoro como sinestésico. Os estímulos de diferentes canais perceptivos funcionam em parceria - de acordo com o observado - assim tem-se o potencial perceptivo ampliado e cada canal pode tanto ter um valor informativo como facilitar a atenção e a aprendizagem.

A Memória do usuário envolve a recordação de conhecimentos diante a necessidade. Foi possível perceber a utilização de diversas formas de feedback às ações do usuário que auxiliavam esse processo cognitivo, incluindo tanto interfaces para memorização de teclas de comando como interfaces para relembrar das decisões tomadas em momentos chaves da narrativa. $\mathrm{O}$ uso de comandos simples, que utilizam elementos gráficos similares aos exibidos na interface física do controle, auxilia o usuário a identificar, memorizar e executar as tarefas de maneira satisfatória.

A união intrínseca de games com a cinematografia elenca uma série de novos princípios específicos desses sistemas, com base nas suas telas de instrução, menus, submenus controles e interfaces interativas. Essas podem ser mantidas ou modificadas a medida que este gênero transforma, 


\section{$16^{\circ}$ \\ ERGODESIGN USIHC CINAHPA}

$16^{\circ}$ Ergodesign - Congresso Internacional de Ergonomia e Usabilidade de Interfaces Humano Tecnológica: Produto, Informações Ambientes Construídos e Transporte

$16^{\circ}$ USIHC - Congresso Internacional de Ergonomia e Usabilidade de Interfaces Humano Computador

CINAHPA | 2017 - Congresso Internacional de Ambientes Hipermídia para Aprendizagem. explorando novos tipos de comandos e interações.

\section{Considerações Finais}

Através desse estudo foi possível perceber que alguns princípios se destacaram como: Alta Carga Cognitiva necessária devido a quantidade de informação disponibilizada no decorrer do jogo. Assim se exige um esforço cognitivo maior do usuário, o que torna fundamental compreender as estratégias interativas para facilitar o aprendizado, a atenção e a memorização; Memorização enquanto processo de aprendizagem, os jogos analisados apresentam em seu início telas de instrução que destacam as possibilidades de comandos, em cenas simples, com um tempo de resposta maior, visando que o jogador memorize e internalize os controles que serão explorados no decorrer do jogo; Utilização mínima de elementos informativos, valorizando a interface lúdica interativa, induzindo o jogador à experiência mais imersiva; Liberdade parcial, ainda que haja a possibilidade de infinitas ações, o sistema restringe o usuário a seguir a narrativa dentro do ambiente digital.

Contudo, foi possível observar a ampla utilização de elementos gráficos com o intuito de gerar redundância da informação. A possibilidade da reprodução e adaptação deste estudo dá relevância à pesquisa realizada, sendo possível aprofundá-la em análises futuras, principalmente para buscar características específicas para cada gênero de jogos digitais que possuem suas individualidades.

\section{BIBLIOGRAFIA}

BARBOSA, S, D, J.; SILVA, B. S. Interação Humano-Computador. Rio de Janeiro: Elsevier, 2010.

\section{BRANDÃO, L. R. Jogos Cinematográficos ou}

Filmes Interativos? A semiótica e a interatividade da linguagem cinematográfica nos jogos

eletrônicos. 11 ed. Brasília - DF: SBGames, 2012. ISSN - 2179-2259.

\section{CRAWFORD, C. The Art of Computer Game}

Design. Washington State University - Vancouver, 1997. Disponícel em: < http://www-

rohan.sdsu.edu/ stewart/cs583/ACGD_ArtComput
erGameDesign_ChrisCrawford_1982.pdf>. Acesso em: 26 set. 2016.

GIL, A. C. Como Elaborar Projetos de Pesquisa. 4. ed. São Paulo: Editora Atlas S.A., 2002.

LUZ, A. R. Linguagens Gráficas em Vídeogame. 2009. 167 P. Dissertação (Mestrado em Design e

Arquitetura) Faculdade de Arquitetura e

Urbanismo da Universidade de São Paulo, São

Paulo.

MORAES, A.; MONT'ALVÃO, C. Ergonomia: Conceitos e aplicações. Rio de Janeiro: 2AB, 2009.

NOVAK, J. Desenvolvimento de Games. São Paulo: Cengage Learning, 2010.

PETTERSON, R. Information Design: An Introduction. Philadelphia: John Benjamins Publishing Company, 2002.

ROGERS, Y.; HELEN, S.; PREECE, J. Design de Interação: Além da Interação HumanoComputador. 3. ed. Porto Alegre: Bookman, 2013.

SANTAELLA, L. Matriz da Linguagem e

Pensamento. 3 ed. São Paulo: Iluminuras, 2005.

SZILAS, N. The Future of Interactive Drama.

Macquaire University, Sidney, 2004. 14 ${ }^{\circ}$

Congresso Internacional de Ergonomia e

Usabilidade, Design de Interfaces e Interação

Humano-Computador. Joinville, 2014. Disponível em $<$

http://tecfa.unige.ch/perso/szilas/papers/Szilas_IE0 5.pdf>. Acesso em: 07 jun. 2016.

XAVIER, G. Cultura Visual nos Jogos

Eletrônicos. Teresópolis: Novas Ideias. 2010. 